\title{
Article \\ Quantifying the Economy-Environment Interactions in Tourism: Case of Gansu Province, China
}

\author{
Chenyu Lu ${ }^{1, *}$, Wenlei Li ${ }^{1}$, Min Pang ${ }^{1}$, Bing Xue ${ }^{2,3}$ (i) and Hong Miao ${ }^{4, *}$ \\ 1 College of Geography and Environment Science, Northwest Normal University, Lanzhou 730070, China; \\ 18298496281@163.com (W.L.); pangminrb172@126.com (M.P.) \\ 2 Key Laboratory of Pollution Ecology and Environmental Engineering, Institute of Applied Ecology, \\ Chinese Academy of Sciences, Shenyang 110016, China; xuebing@iae.ac.cn \\ 3 Key Lab for Environment Computation and Sustainability of Liaoning Province, \\ Institute of Applied Ecology, Chinese Academy of Sciences, Shenyang 110016, China \\ 4 College of Resource and Environment, Ningxia University, Yinchuan 750021, China \\ * Correspondence: luchenyu@nwnu.edu.cn (C.L.); miao_h@nxu.edu.cn (H.M.)
}

Received: 25 January 2018; Accepted: 4 March 2018; Published: 6 March 2018

\begin{abstract}
Together, the regional economy, tourism industry, and ecological environment form mutually interactive and interdependent relationships. Therefore, a better understanding of their evolutionary relationships could help reveal the spatial-temporal evolution patterns of their coordinated development and promote a successful implementation of strategies for regional sustainable development. By choosing the 14 cities (12 cities and 2 city-level prefectures) in Gansu Province as cases, this study establishes the respective evaluation indices for assessing the coordinated developmental level of the tourism system. With a combination of varying quantitative methods including order parameter analysis, fuzzy membership classification, regression analysis and gray correlation analysis, measurement models for assessing the coordinated developmental level and analyzing the associated spatial-temporal evolution patterns are established between 2000 and 2016. The conclusions are as follows. Between 2000 and 2016, the development of the regional economy, tourism industry, and ecological environment mutually reinforced one another in Gansu Province. Overall, the coordinated developmental level kept gradually improving over time. However, the development of the ecological environment lagged behind that of the tourism industry and economic growth, and synchronous and coordinated development among these three subsystems was not achieved. The overall level of coordination among 14 cities was also gradually improved, as manifested by the good level of coordinated development. However, spatial differences still existed.
\end{abstract}

Keywords: tourism; economy; environment; coordinated development

\section{Introduction}

\subsection{Background}

With continuous improvement in productivity levels accompanied by rapid industrialization and urbanization processes, people's standard of living is continually improving and their disposable incomes are rising. At the same time, the fact that people have more leisure time and improvements to public transportation systems are allowing an increasing amount of people to discover the joys of tourism. According to an estimation by the World Travel \& Tourism Council (WTTC), the overall contribution of the tourism industry to global GDP (Gross Domestic Product) was 8.2 trillion USD in 2016, or 11\% of global GDP. Furthermore, the tourism industry has generated 290 million jobs, or $10 \%$ of total jobs worldwide. Although the tourism industry in China was behind that of other countries, the fast-growing economy and a supportive environment, i.e., the country's reforms and 
opening-up policies, have led to the rapid development of the tourism industry in this country [1]. According to official statistics released by China's National Tourism Administration, the number of domestic tourists in China reached 4.44 billion, with tourism revenue amounting to 4 trillion RMB in 2016. At the same time, the number of outbound tourists reached 122 million, and outbound tourism expenditure was 220 billion US Dollars, with both categories ranking 1st worldwide. Tourism has become one of the important pillar industries of China's economic development, and it is a new growth point of consumption, investment and export function [2,3]. However, due to lagging legislation within the tourism industry, and many blind spots in its laws and regulations, the rapid development of tourism's economic benefits in some regions is at the expense of the quality of the ecological environment. As a result, the disruption of the regional ecological balance will not only interfere with the natural cycle of the ecosystem, but also reduce the attractiveness of tourist destinations. Additionally, this disruption will prevent tourists from gaining a good perception of the benefits of tourism, constrain the development of the regional tourism industry, and to a certain extent slow down the pace of regional economic development. Therefore, in order to enhance regional development, it is necessary to study the interactive and evolutionary relationships between these three factors to promote a balanced and coordinated development.

Gansu Province consists of 14 cities (12 cities and 2 city-level prefectures), located in northwest China, endowed with various resources that are attractive to tourists. Gansu needs to grasp the great opportunities that have arisen due to the implementation phase of the Western Development Strategy and take full advantages of the area's rich tourism resources, promote both special interest tourism and refined tourism so that its tourism industry can develop more rapidly. For instance, during 2000 and 2016, the average annual growth rate of the total number of tourists was up to $51.8 \%$ and the total tourism revenue was up to $44.5 \%$, which increased from 2.31 billion RMB to 121.9 billion RMB. The proportion of tourism revenue has grown to $10 \%$ of GDP and $25 \%$ of the tertiary industry in 2016 . Therefore, tourism has become one of the important pillar industries in Gansu Province. However, Gansu Province is located in the heart of the northwest inland known for its arid climate, limited precipitation and fragile ecological environment. At the same time, the overexploitation of coal, oil, natural gas and other energy resources has considerably exacerbated the situation. Therefore, if the development and utilization of tourism resources lack effective protection measures, the ecological environment will be overwhelmed, which would further constrain the sustainable development of the tourism industry, economic growth and ecological environment in Gansu Province [4]. Therefore, it is necessary for Gansu Province to improve its tourism development and pay more attention to scientific planning and the rational exploitation of tourism resources in the tourism development. On the one hand, the development of tourism in Gansu Province is in line with the background, trajectory and process of rapid tourism development in China. On the other hand, the ecological environment in Gansu Province is fragile. Therefore, it is typical and representative to choose Gansu Province and its subordinate cities and prefectures as the case study areas in the present study.

\subsection{The Review of Literatures}

According to foreign academics, research into the coordinated development of regional tourism industries and economic growth focuses on three major research directions: the impact of the regional tourism industry on an economy, the impact of the regional economy on the tourism industry, and the interactive relationship between a region's economy and the tourism industry. For example, Milman [5] studied the impact of the tourism industry on the regional economy, and concluded that tourist consumption could, to a certain extent, promote the economic development of tourist destinations. Furthermore, Oh [6] studied the impact of the regional economy on the tourism industry in South Korea using co-integration theory and the Granger causality test, and found out that regional economic growth could accelerate the development of the tourism industry. Finally, Lee [7] used panel data to study the relationship between the national tourism industry and economic growth in non-OECD (Organization for Economic Co-operation and Development) and Latin America countries, and found 
out that the development of the tourism industry could promote regional economic development. Domestic scholars also have kept up with international research to study the interactive relationship between the regional economy and tourism industry. For example, Cao [8] used a qualitative analysis to study the interactive relationship between the regional economy and leisure sports industry in the Yangtze River Delta; the study was based on relevant theoretical methods developed by scientists from Europe and the United States, with the core ideas of "regional planning" and characteristics of economic development taken fully into account. With regard to quantitative analysis, by utilizing relevant theories and methods developed in different disciplines, domestic scholars have established co-integration models, coupling models and gear models to study the interactive relationship between the regional economy and tourism industry. For example, Liu [9] analyzed data collected from 31 provinces, autonomous regions and municipalities in China, and analyzed the interactive and interdependent relationship between the regional economy and tourism industry by using an established coupling coordination degree model.

Foreign researchers began to address the question of how the tourism industry, and ecological environment interact with one another earlier than domestic researchers. Indeed, they began to observe and describe the impact of the tourism industry on the ecological environment as far back as 1920s. Since then, as the contradiction between the tourism industry and ecological environment became increasingly prominent, academics from Europe, the United States and other developed countries have continued to conduct follow-up or in-depth research covering three major areas of research. The first area focuses on the impact of regional tourism on the ecological environment. In this relationship between the two, that is, the change of ecological environment is the result of tourism development. For example, based on the concept of resource utilization intensity, Gossling [10] concluded that the heavy resource consumption in tourism activities made the ecological environment increasingly fragile. Through empirical research, Karim [11] concluded that tourism activities were the main cause of quality deterioration of water and air. The second area focuses on the impact of the regional ecological environment on the tourism industry. In this relationship between the two, that is, the tourism development is the result of ecological environment. For example, by exploring the impact of the ecological environment on the tourism industry in Spain, Hein [12] concluded that the former imposed a constraining impact on the latter. The third area focuses on the interactive relationship between the regional tourism industry and ecological environment. In this relationship between the two, that is, the ecological environment and tourism interact as both cause and effect. For example, Day [13] used the United States and China as case studies to explore the interactive relationship between the regional tourism industry and ecological environment, and their findings showed that the former imposed substantial pressure on the latter, and the latter restricted the development of the former. An [14] studied the relationship between tourism development and ecological environment and concluded that the tourism activities led to the deterioration of the ecological environment, and the ecological environment had a certain reaction to the tourism as well. In recent years, domestic researchers have paid a great deal of attention to the interactive relationship between the regional tourism industry and ecological environment, with a specific focus on how to more scientifically and quantitatively determine a potentially coordinated relationship between the two, and how to conduct research at different spatial scales. For example, based on the model of coordinated development degree, Zhang [15] analyzed the coupling coordinated development between tourism and ecological environment in Jiangxi Province. Based on the model of coupling coordination degree, Han [16] measured the coupling coordination degree between tourism and ecological environment in the Yangtze river delta and analyzed the spatial and temporal evolution of coupling coordination degree.

Therefore, gaining an understanding of the relationship between economic growth and the ecological environment, and formulating countermeasures for the sake of sustainable development remains a topic of great interest in the academic world [17-19]; however, foreign researchers have put a different focus on the interactive relationship between the two due to different stages of 
economic and social development. In the late 1980s, the development of the dynamic analysis of the eco-economic system led to the rise of ecological economics. In the early 1990s, foreign academics started to use the environmental Kuznets curve to conduct a quantitative analysis on the subject of coordinated development between economic growth and the ecological environment. For example, Grossman [20] and Caviglia-Harris [21] used the environmental Kuznets curve to conduct an empirical study on the coordinated relationship between economic development and the ecological environment across different regions. Due to continuous economic and social development, these researchers switched to measurement models to analyze the coordinated relationship. For example, Bithas [22] developed coordination models to study the relationship between economic growth and the ecological environment based on the Expert Knowledge System due to uncertain or unknown information. Since the beginning of the 21st century, with the development of related disciplines theory, diverse analytical methods and mathematical models have become available due to the development of multiple theories and methods from different disciplines. For example, Stave [23] and Oliveira [24] analyzed the interactive relationship between economic growth and the ecological environment through the use of the multi-objective linear programming evaluation model, with input-output analysis as its essential principle. Domestic researchers however, only began to study the interactive relationship between the regional economy's development and the ecological environment in the 1980s. Having taken the actual situation of the study area fully into account, and with a combination of different analytical methods, multiple evaluation models were developed to quantitatively analyze the coordinated relationship between the regional economy and ecological environment across different spatial scales. For example, Yang [25], Cai [26], Ren [27] and Zhang [28] applied the barometer of sustainability, polygon synthetic indicator evaluation method and principal component analysis to conduct an empirical study regarding the coordinated relationship between economic growth and the ecological environment at a provincial level.

An area of great interest in current research is to ascertain how the regional economy, tourism industry and ecological environment interact with one another, and how to accurately measure the level of coordination among these three subsystems. Foreign academics generally tend to focus on the coordinated relationship in paired subsystems with all possible combinations. For example, Petrosillo [29] and Lacitignola [30] established a model that could reflect the relationship between the economic society and environmental quality on the basis of the tourism industry's development. Moreover, Wei [31] applied concepts and tools adapted from mathematical theories to analyze the sustainable relationship between regional tourism development and the social-ecological system. Compared with foreign researchers, domestic scholars have made some substantial gains regarding the coordinated relationship between the regional economy, tourism industry and ecological environment, with a focus on a temporal evolution analysis across different spatial scales; however, less attention has been paid to spatial evolution analysis. Several academics conducted their research at the provincial or regional level. For example, Zhou [32] analyzed the coupling coordination level of provinces along the Yangtze Economic Zone from temporal and spatial dimension based on the coupling model. Other studies were conducted at the city level. For example, Xiong [33] introduced the coordinated development degree model to study the level of coordinated development between the regional economy, tourism industry and ecological environment in Zhangiajie City between 1996 and 2010.

Overall, foreign and domestic researchers have done some excellent work in exploring topics such as how to evaluate the level of coordinated development between the regional economy, tourism industry and ecological environment, both qualitatively and quantitatively, from a variety of different angles and perspectives. Nevertheless, although they have achieved a great deal, certain problems still exist. First, a large number of studies have focused on the development of coordination degree models and subsequent evaluations between subsystems, but the level of coordination within subsystems has received less attention. Furthermore, available literature that explicitly considers the degree of coordination within and between subsystems in a systematic manner is very limited. Second, a large number of studies have focused on the provincial level or prefectural-level cities singly, and temporal 
or spatial dimension singly. The integrated research from both provincial level and prefectural-level cities is very limited. Therefore, the current study uses 14 cities and prefectures in Gansu Province as the study object, strives to develop a comprehensive measurement model that integrates within- and between-system levels of coordination between the regional economy, tourism industry and ecological environment, as well as the coordinated development degree, and applies the model to conduct a temporal-spatial evolution analysis of the coordinated development of our study object between 2000 and 2016, with the aim, as far as possible, of providing some elements of complementarity.

\subsection{Structure and Contribution}

This study chooses Gansu Province and its 14 cities (12 cities and 2 city-level prefectures) as the research area and establishes the evaluation index system of coordinated development of tourism, economy and ecological environment. A comprehensive assignment method combining the subjective analytic hierarchy process and the objective entropy method is used to determine the weight of each index. Furthermore, with a combination of varying quantitative methods, including order parameter analysis, fuzzy membership classification, regression analysis and gray correlation analysis, measurement models for assessing the coordinated development level are established. Then, the within-system coordination degree, the between-system coordination degree and the coordination development degree of tourism, economy and ecological environment are calculated from 2000 to 2016, and the associated temporal and spatial evolution is analyzed.

This research has a certain innovation, that is, it can complement and improve the deficiencies of existing literature. First of all, the research method is innovative. This research uses the order parameter analysis, fuzzy membership classification, gray correlation analysis and other quantitative methods, to establish the measurement models of the within-system coordination degree, the between-system coordination degree and the coordination development degree of tourism, economy and ecological environment. Secondly, the research perspective is innovation. Based on different scales, this research combines the provincial level and prefecture-level to conduct the comprehensive measure and comparative analysis of temporal and spatial evolution of coordinated development of tourism, economy and ecological environment. These two aspects are the contribution of this research to the existing academic literature. In summary, the current study provides solutions and suggestions to help solve some existing research problems, with important theoretical and practical significance. It also offers a useful reference for the development of the regional tourism industry, as well as for executive government departments to create policies related to a coordinated and balanced development between the regional economy, tourism industry and ecological environment, as well as the promotion of sustainable development.

\section{Materials and Methods}

\subsection{The Development of an Evaluation Index System of Coordinated Development}

Gansu Province consists of 14 cities (12 cities and 2 city-level prefectures), located in northwest China (Figure 1). Based on the actual situation of Gansu Province, the evaluation index system consists of the provincial level and prefectural-level cities in this study. The former pays attention to the characteristics of the large-scale area (Gansu Province). Therefore, in order to highlight the characteristics of provincial integrality more objectively and scientifically, the evaluation index system at the provincial level mainly reflects the overall development of tourism, economy and ecological environment in Gansu Province. The latter pays attention to the common characteristics of the municipal scale area (cities and prefectures). Therefore, it is necessary to consider the differences in tourism, economy and ecological environment of various cities and the universality of the evaluation index when establishing the evaluation index system of prefectural-level cities. Eventually, based on the frequency statistics and expert consultation, the evaluation index system was established, which consists of target layer, system layer, criterion layer and index layer. Herein, the direction of 
" + " means the indicator is positive, that is, the larger the value is, the better the system is. On the contrary, the direction of " - " means the indicator is negative, that is, the larger the value is, the worse the system is.

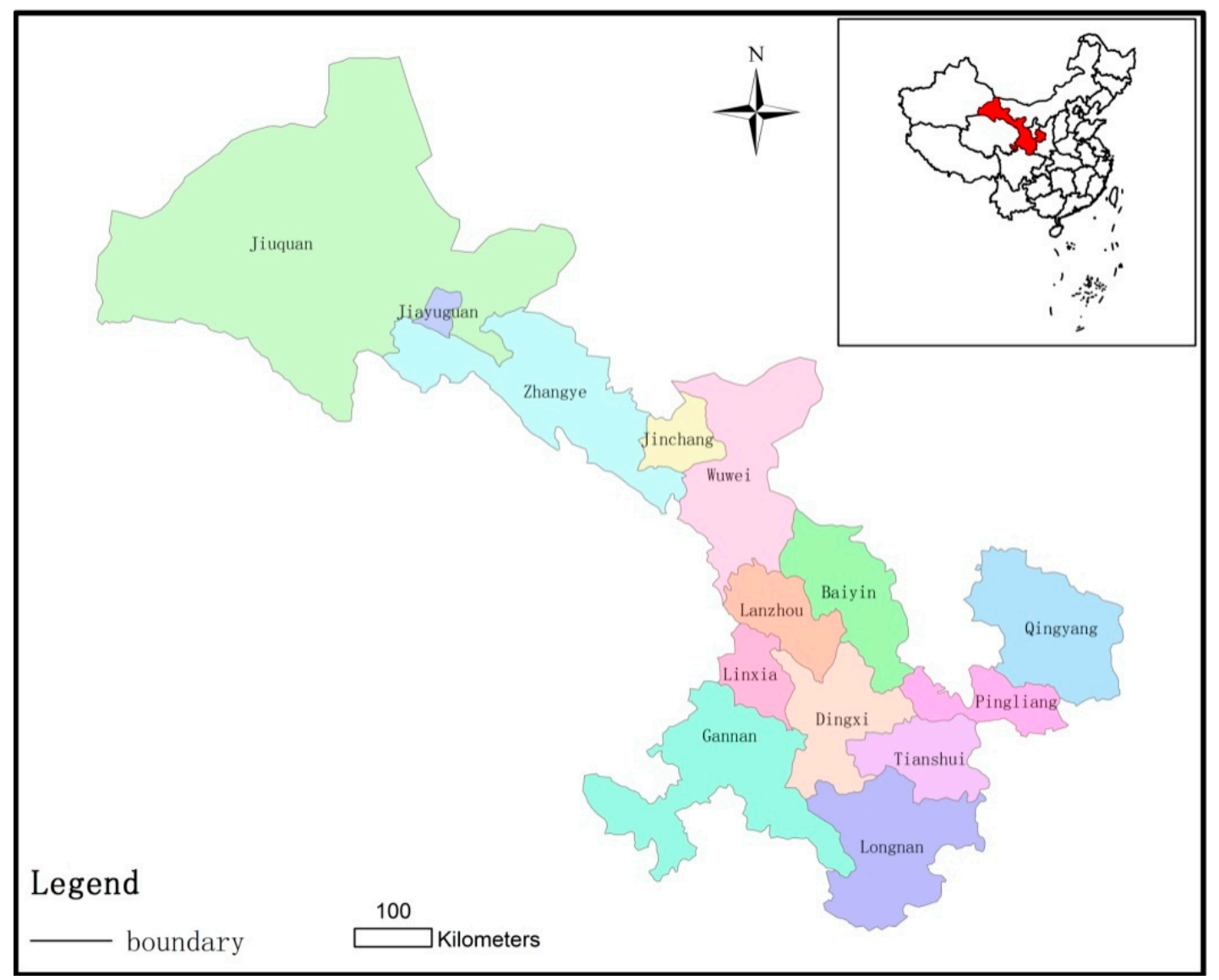

Figure 1. The map of Gansu Province.

The evaluation index system at the provincial level is shown in Table 1. And the evaluation index system of prefectural-level cities is shown in Table 2. The weights in Table 1 show that, for provincial level, number of total tourists, the contribution of tourism to GDP, the contribution of tertiary industries to GDP, industrial wastewater standard-reaching wastewater discharge rate, the comprehensive utilization rate of industrial solid waste, product value of three wastes' comprehensive utilization, and green coverage rate in recently established areas, these seven indexes are more important than other indexes. The contribution of these seven indexes is significant, and the total contribution rate of these seven indexes is about one-third in the evaluation process. The weights in Table 2 show that, for prefectural-level cities, total tourism revenue, total retail sales of consumer goods, and green coverage rate in recently established areas, these three indexes are more important than other indexes. The contribution of these three indexes is significant in the evaluation process. 
Table 1. The evaluation index system at the provincial level.

\begin{tabular}{|c|c|c|c|c|c|}
\hline Target & System & Criteria & Index & Direction & Weight \\
\hline \multirow{31}{*}{$\begin{array}{l}\text { Evaluation of the coordinated development } \\
\text { of economic growth, the tourism industry } \\
\text { and ecological environment }\end{array}$} & \multirow{10}{*}{ Tourism industry } & \multirow{5}{*}{ The scale of tourism } & Number of international tourists & + & 0.034 \\
\hline & & & Number of domestic tourists & + & 0.038 \\
\hline & & & Number of total tourists & + & 0.043 \\
\hline & & & Turnover of tourists & + & 0.027 \\
\hline & & & Number of star-rated hotels & + & 0.016 \\
\hline & & \multirow{5}{*}{ Economic benefits of tourism } & International tourism revenue & + & 0.030 \\
\hline & & & Domestic tourism revenue & + & 0.013 \\
\hline & & & Total tourism revenue & + & 0.038 \\
\hline & & & The contribution of tourism to GDP & + & 0.046 \\
\hline & & & The contribution of tourism to tertiary industries & + & 0.034 \\
\hline & \multirow{12}{*}{ Economic growth } & \multirow{3}{*}{ The scale of the economy } & GDP per capita & + & 0.037 \\
\hline & & & Fixed-asset investment per capita & + & 0.018 \\
\hline & & & Per capita income & + & 0.022 \\
\hline & & \multirow{2}{*}{ Economic activity } & GDP growth rate & + & 0.036 \\
\hline & & & Total retail sales of consumer goods & + & 0.020 \\
\hline & & Economic efficiency & Output-to-input ratio & + & 0.022 \\
\hline & & \multirow{2}{*}{ Economic structure } & The contribution of primary industries to GDP & - & 0.026 \\
\hline & & & The contribution of tertiary industries to GDP & + & 0.045 \\
\hline & & \multirow{4}{*}{ The level of social development } & Rural per capita net income & + & 0.029 \\
\hline & & & Per capita disposable income of urban residents & + & 0.027 \\
\hline & & & Engel coefficient of rural residents & - & 0.037 \\
\hline & & & Engel coefficient of urban residents & - & 0.031 \\
\hline & \multirow{9}{*}{ Ecological environment } & \multirow{3}{*}{ Environmental pollution } & Total discharge of industrial wastewater & - & 0.031 \\
\hline & & & Total emission by industries & - & 0.032 \\
\hline & & & Total amount of industrial solid waste & - & 0.027 \\
\hline & & \multirow{3}{*}{ Environmental Protection } & Industrial wastewater Standard-reaching wastewater discharge rate & + & 0.045 \\
\hline & & & The comprehensive utilization rate of industrial solid waste & + & 0.054 \\
\hline & & & Product value of three wastes' comprehensive utilization & + & 0.041 \\
\hline & & Ecological environment conditions & Public green spaces per capita & + & 0.022 \\
\hline & & & Afforestation areas within a year & + & 0.037 \\
\hline & & & Green coverage rate in recently established areas & + & 0.042 \\
\hline
\end{tabular}


Table 2. The evaluation index system of prefectural-level cities.

\begin{tabular}{|c|c|c|c|c|c|}
\hline Target & System & Criteria & Index & Direction & Weight \\
\hline \multirow{9}{*}{$\begin{array}{l}\text { Evaluation of the coordinated } \\
\text { development between economic } \\
\text { growth, the tourism industry and } \\
\text { ecological environment }\end{array}$} & \multirow{4}{*}{ Tourism industry } & The scale of tourism & Number of total tourists & + & 0.087 \\
\hline & & \multirow{3}{*}{ Economic benefits of tourism } & Total tourism revenue & + & 0.091 \\
\hline & & & The contribution of tourism to GDP & + & 0.085 \\
\hline & & & The contribution of tourism to tertiary industries & + & 0.084 \\
\hline & \multirow{3}{*}{ Economic growth } & The scale of the economy & GDP per capita & + & 0.079 \\
\hline & & Economic efficiency & Output-to-input ratio & + & 0.068 \\
\hline & & Economic activity & $\begin{array}{l}\text { Total retail sales of consumer goods } \\
\text { GDP growth rate }\end{array}$ & $\begin{array}{l}+ \\
+ \\
\end{array}$ & $\begin{array}{l}0.095 \\
0.086\end{array}$ \\
\hline & \multirow{2}{*}{ Ecological environment } & Environmental pollution & $\begin{array}{l}\text { The amount of rubbish cleared } \\
\text { Air pollution index }\end{array}$ & - & $\begin{array}{l}0.073 \\
0.082 \\
\end{array}$ \\
\hline & & Ecological environment conditions & $\begin{array}{l}\text { Public green spaces per capita } \\
\text { Green coverage rate in recently established areas }\end{array}$ & $\begin{array}{l}+ \\
+\end{array}$ & $\begin{array}{l}0.076 \\
0.094\end{array}$ \\
\hline
\end{tabular}




\subsection{Data Sources and the Processing of Data}

All data used in the current study were derived from China's Statistical Yearbook, China's Tourism Statistical Yearbook, Statistical Yearbook of Gansu Province and other municipalities, China's Statistical Bulletin of National Economic and Social Development, China's Environment Statistical Yearbook, as well as data provided by Department of Statistics, Department of Tourism, Department of Environmental Protection and other government sectors of Gansu Province and other municipalities. For data analysis, all indicator data were first standardized and normalized, and then a comprehensive weight assignment method was applied, which was a combination of the analytic hierarchy process of synthesizing subjective criteria and the cross-entropy method of synthesizing objective criteria with specific weights assigned to each indicator. The advantage of entropy method is that it can avoid the subjective randomness in the process of weight assignment, and the disadvantage is that it is more rigid, which is not conducive to the flexible analysis of the concrete situation. On the contrary, the advantages of analytic hierarchy process are more flexible, which can be combined with specific situations and characteristics, but the disadvantage is more arbitrary. Therefore, the combination of two methods can effectively avoid their own defects and learn from each other.

Assuming the weight of the subjective and objective assignment of index $j$ are $w_{c j}$ and $w_{s j}$, the weight of comprehensive assignment is $w_{j}$ :

$$
w_{j}=\left(w_{c j} \times w_{s j}\right) /\left(\sum_{j=1}^{n} w_{c j} \times w_{s j}\right)
$$

The weight of subjective assignment is based on the results of different experts' marking, taking their average, and then calculated by the analytic hierarchy process. The weight of objective assignment is calculated by entropy method.

\subsection{The Establishment of Measurement Models of the Coordinated Development}

\subsubsection{Measurement Models of the Coordination Degree within Systems}

The coordination degree model with order parameters is used to measure the coordination degree of complex system. There are two kinds of internal variables at the phase transition point of the system in synergy theory, fast and slow, and the slow one is the fundamental variable to determine the system phase transition process, which is called the order parameter of the system. The synergistic effect of the internal variables at the critical point determines the phase transition process, evolution direction and coordinated state of the system. There are two kinds of effects on the degree of order when the order parameters have changes in a stable system, one is positive effect, that is, larger the order parameter is, better the degree of order is, and the other is negative, that is, smaller the order parameter is, better the degree of order is. In the current study, when the coordination degree within systems of the regional economy, tourism industry and ecological environment is quantified, the linear weighting method is applied to the coordination degree evaluation model with order parameters. The formula is shown as follows:

$$
u=\sum_{j=1}^{n} w_{j} u\left(X_{i j}\right), w_{j} \geq 0, \sum_{j=1}^{n} w_{j}=1
$$

where $u$ represents the coordination degree within each subsystem, $w_{j}$ represents the relative importance of order parameter $X_{j}$, and $u\left(X_{i j}\right)$ represents the degree of order, $u\left(X_{i j}\right) \in[0,1]$; the larger its value is, the higher its contribution to the level of coordination within each subsystem, and vice versa.

$$
\begin{aligned}
& \text { Positive effect indicators: } u\left(X_{i j}\right)=\left(X_{i j}-X_{\min }\right) /\left(X_{\max }-X_{\min }\right) \\
& \text { Negative effect indicators: } u\left(X_{i j}\right)=\left(X_{\max }-X_{i j}\right) /\left(X_{\max }-X_{\min }\right)
\end{aligned}
$$


where $u\left(X_{i j}\right)$ represents the degree of order of $X_{i j}$, which is the actual value of index $j$ in phase $i$. $X_{\max }$ and $X_{\min }$ are the maximum and minimum of the same index in different periods.

\subsubsection{Measurement Models of the Coordination Degree between Systems}

Fuzzy system is a promotion of the deterministic system, which defines the input, output and state variables on fuzzy sets. Membership function is a mathematical tool used to characterize fuzzy sets. In the current study, when the level of coordination between the regional economy, tourism industry and ecological environment is quantified between systems, the coordination degree evaluation model with a fuzzy membership function is selected. Besides, the principal component analysis and the regression analysis are also used. The former aims to transform the multiple indicators into a few comprehensive indicators by reducing the dimension. Then it is possible to get the scores of principal components to make a comprehensive evaluation. The latter is a statistical analysis method to determine the interdependent quantitative relationship between two or more variables. The formula is shown as follows:

$$
u(i / j)=\exp \left[-\frac{\left(x_{i}-x^{\prime}\right)^{2}}{S_{i}^{2}}\right]
$$

where $u(i / j)$ represents the coordinating conditional degree; $x_{i}$ represents the comprehensive development index of system $i$, which can be calculated by principal component analysis method; $x^{\prime}$ represents the predicted value of system $i$ in response to the requirement of system $j$; and $S_{i}{ }^{2}$ represents the variance of the comprehensive development index of system $i$. To calculate the $x^{\prime}$, first, it is necessary to calculate the comprehensive development index of systems $i$ and $j$ by principal component analysis method. Second, take the comprehensive development index of systems $i$ and $j$ respectively as the dependent variable and independent variable, fit the regression equation, and then put the actual value of system $j$ into the equation, the corresponding predictive value $x^{\prime}$ can be calculated.

Through the use of the coordinating conditional degree, the coordination degree between two systems, $U(i, j)$, can be calculated. The specific formula is shown as follows:

$$
U(i, j)=\frac{\min \{u(i / j), u(j / i)\}}{\max \{u(i / j), u(j / i)\}}
$$

where $U(i, j)$ represents the coordination degree between system $i$ and $j ; u(i / j)$ represents the coordinating conditional degree of system $i$ relative to system $j$; and $u(j / i)$ represents the coordinating conditional degree of system $j$ to system $i . U(i, j) \in[0,1]$. The closer the value to 1 is, the higher the coordination degree between system $i$ and $j$, and vice versa.

The coordination degree between the three systems can be calculated using the following formula:

$$
U(i, j, k)=\left[\begin{array}{c}
u(i / j, k) \times U(j, k) \\
+u(j / i, k) \times U(i, k) \\
+u(k / i, j) \times U(i, j)
\end{array}\right] /\left[\begin{array}{c}
U(j, k) \\
+U(i, k) \\
+U(i, j)
\end{array}\right]
$$

where $U(i, j, k)$ represents the coordination degree between system $i, j$ and $k ; u(i / j, k)$ represents the coordinating conditional degree of system $i$ to system $j$ and $k ; U(j, k)$ represents the coordination degree between system $j$ and $k ; u(j / i, k)$ represents the coordinating conditional degree of system $j$ to system $i$ and $k ; U(i, k)$ represents the coordination degree between system $i$ and $k ; u(k / i, j)$ represents the coordinating conditional degree of system $k$ to system $i$ and $j$; and $U(i, j)$ represents the coordination degree between system $i$ and $j . U(i, j, k) \in[0,1]$. The closer the value to 1 is, the higher the coordination degree between systems, and vice versa. 


\subsubsection{Measurement Models of the Coordinated Development}

To assess whether the regional economy, tourism industry and a region's ecological environment is developed in a coordinated and sustainable manner, it is important to make a comprehensive measurement of the coordination degree and development level index within and between subsystems. Accordingly, the present study establishes an index evaluation system to assess the level of coordinated development (Table 3).

Table 3. The evaluation index system of coordinated development.

\begin{tabular}{|c|c|c|}
\hline Target & Criteria & Index \\
\hline \multirow{7}{*}{$\begin{array}{l}\text { Evaluation of the level of coordinated } \\
\text { development between economic growth, } \\
\text { the tourism industry and } \\
\text { ecological environment }\end{array}$} & \multirow{6}{*}{ Coordination degree } & $\begin{array}{l}\text { The coordination degree within the tourism } \\
\text { industry subsystem }\end{array}$ \\
\hline & & The coordination degree within the economic subsystem \\
\hline & & $\begin{array}{l}\text { The coordination degree within the ecological } \\
\text { environment subsystem }\end{array}$ \\
\hline & & $\begin{array}{l}\text { The coordination degree between the tourism industry and } \\
\text { economic growth }\end{array}$ \\
\hline & & $\begin{array}{c}\text { The coordination degree between the tourism industry and } \\
\text { ecological environment }\end{array}$ \\
\hline & & $\begin{array}{l}\text { The coordination degree between the tourism industry, } \\
\text { economic growth and the ecological environment }\end{array}$ \\
\hline & Development degree & $\begin{array}{c}\text { The comprehensive development index of the ecological } \\
\text { environment subsystem }\end{array}$ \\
\hline
\end{tabular}

When evaluating comprehensive coordinated development, there are many influencing factors and complicated relations. At the same time, it is difficult to define the degree of coordinated development. Therefore, a certain of fuzzification is existing when evaluating the comprehensive coordinated development degree. On this basis, the present study applies the gray correlation fuzzy evaluation model to quantify the coordination degree. The main calculation steps are as follows. First, determine the evaluation index system and get an initial matrix. Second, calculate the fuzzy membership degree and determine the optimal index set, that is, finding out the optimal value of each index, and put it in the first row of the initial matrix to get a new matrix, and then the dimensionless standardization is needed. Third, calculate the gray correlation coefficient using the gray correlation analysis, and then construct the fuzzy relational matrix $R$, lastly, the comprehensive evaluation is carried out. The formula is shown as follows:

$$
B=R \cdot P=\left[\begin{array}{cccc}
r_{11} & r_{12} & \cdots & r_{1 n} \\
r_{21} & r_{22} & \cdots & r_{2 n} \\
\cdots & \cdots & \ddots & \cdots \\
r_{m 1} & r_{m 2} & \cdots & r_{m n}
\end{array}\right]\left[\begin{array}{c}
P_{1} \\
P_{2} \\
\cdots \\
P_{n}
\end{array}\right]=\left[\begin{array}{c}
b_{1} \\
b_{2} \\
\cdots \\
b_{m}
\end{array}\right]
$$

where $B$ represents the comprehensive coordinated development degree; $P$ represents the weight of each index, $P_{j} \in[0,1]$, and $P_{1}+P_{2}+\ldots+P_{n}=1$; and $R$ represents a matrix format of fuzzy relations, for which $r_{i j}(i=1,2, \ldots, m ; j=1,2, \ldots, n)$. In other words, when the data are simplified to a dimensionless standardized form, the gray correlation coefficient between the index value of the evaluation object and the optimal index is calculated; finally, $b_{i}(i=1,2, \ldots, m)$ represents the comprehensive evaluation value. The larger $b_{i}$ is, the higher the evaluation effect of coordinated development.

According to the formula used to calculate the degree of coordinated development, the higher the coordinated development degree is, the more likely a region is to display coordinated development, 
and vice versa. With reference to the relevant criteria [34], the present study categorizes coordinated development as five subtypes; namely, extremely uncoordinated, uncoordinated, basically coordinated, fairly coordinated, and highly coordinated (Table 4).

Table 4. Metrics for the coordinated development level.

\begin{tabular}{cccccc}
\hline Range & $0-0.22$ & $0.22-0.44$ & $0.44-0.66$ & $0.66-0.88$ & $0.88-1$ \\
\hline Category & extremely uncoordinated & uncoordinated & basically coordinated & fairly coordinated & highly coordinated \\
\hline
\end{tabular}

\section{Results and Discussion}

\subsection{The Assessment and Analysis of the within-System Coordination Degree}

\subsubsection{The Assessment and Analysis Based on Gansu Province}

It can be seen from Figure 2 that between 2000 and 2016, the coordination degree within subsystems in Gansu Province was mainly manifested in the following aspects: ordinal parameters of various evaluation indicators from either the tourism or economy subsystem displayed a clear upward trend over time, and the coordination degree within either subsystem was substantially strengthened. By contrast, the coordination degree within the ecological environment subsystem kept increasing between 2000 and 2010, but this was followed by a rapid drop in 2011 and a gradual increase afterwards. Compared with other subsystems, the variance of amplitude in terms of the coordination degree was relatively higher within the ecological environment subsystem. Other scholars also have carried out some relevant researches. The representative example is Zhou's research. Zhou [32] took all the provinces in Yangtze Economic Zone as an example, analyzed the evolution of coordinated development of the tourism industry, regional economy and ecological environment. The results showed that coordinated degree of each system experienced stable or fluctuant increase. It is in correspondence with the result of this study. It also shows the evolution of coordinated development of tourism industry, regional economy and ecological environment at provincial level in China.

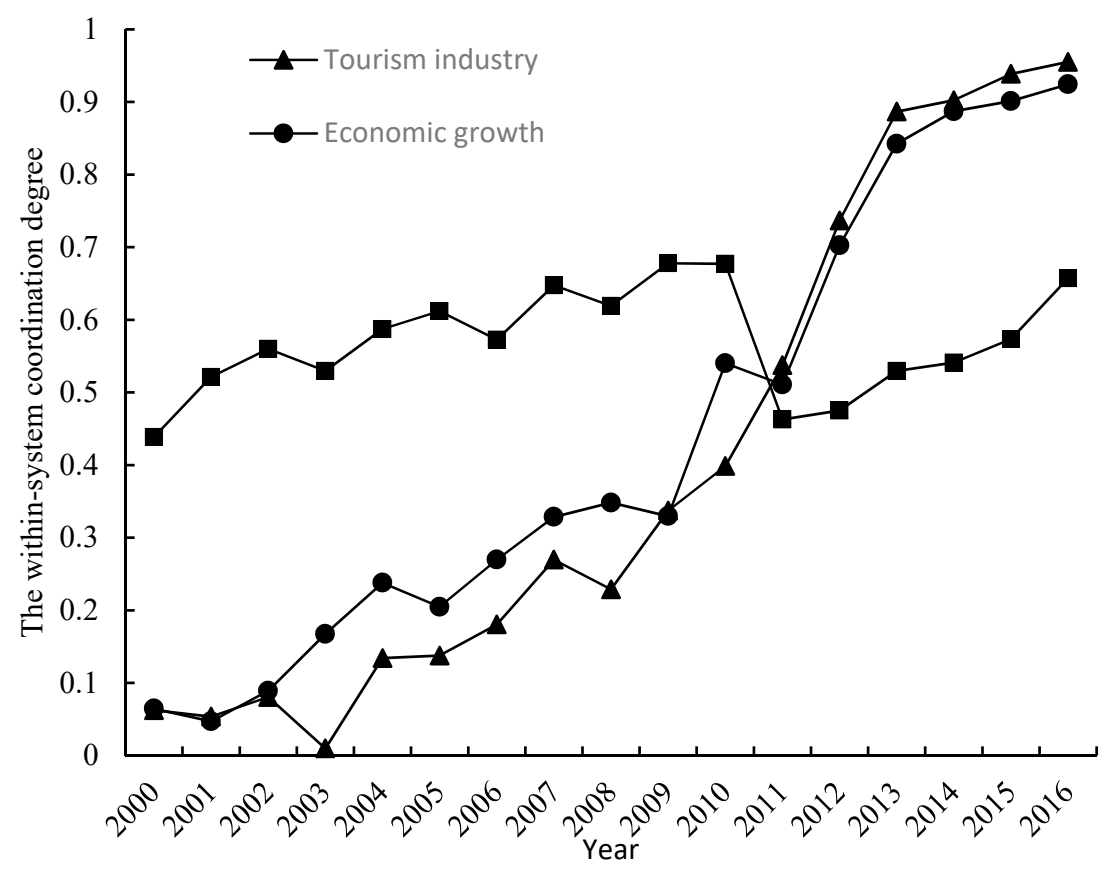

Figure 2. The within-system coordination degree of Gansu Province. 


\subsubsection{City-Level Assessment and Analysis}

The evaluation and analysis of cities and prefectures can only be carried out by selecting typical years, and just need to analyze the general characteristics. Furthermore, the national economic and social development plan in each district is 5 years for a cycle, considering the consistency of time, it is appropriate to take 5 years as the interval standard of time, and select the typical years to carry out the research. Although, considering that the interval standard of 5 years is longer and it is easy to ignore the details in short term, this study takes 3 years as the interval standard. Then 5 typical years of 2001, 2004, 2007, 2010, 2013 and 2016 were selected for this research. According to the coordination measurement model, the coordination degree within the regional tourism, economic growth and ecological environment subsystems of all the 14 cities in Gansu Province in 2001, 2004, 2007, 2010, 2013 and 2016 was quantified, with A representing the tourism industry, B representing the regional economy, and $C$ representing the ecological environment.

It can be seen from Table 5 that between 2001 and 2016, the overall coordination degree of the tourism industry in 14 cities of Gansu Province displayed a promising trend. In summary, although the tourism industry in Gansu Province was late starting, it has demonstrated a remarkable development due to the continuous optimization of the industrial structure and national support of tertiary industries. From the perspective of spatial distribution, there are obvious regional differences among cities and prefectures in terms of the level of coordination within the tourism industry. The patterns of spatial distribution showed that Tianshui, Lanzhou and Jiuquan (Hexi Corridor) represented the center of the eastern, central, and western part of Gansu Province, respectively. Overall, the highest level of coordination was found in the northwest Hexi Corridor and central part of Gansu Province, the intermediate level was found in the south Hexi Corridor and Longzhong Loess Plateau, whereas the lowest level of coordination was found in the Longdong Loess Plateau. Such distribution patterns were mainly caused by a combination of factors, including differences among cities and prefectures in terms of tourism resources, the level of economic and social development, transportation infrastructure, the comfort of, and convenience for, tourists, as well as the bias of government policies.

As far as the coordination degree within the regional economy was concerned, the average level of coordination across 14 cities in Gansu Province displayed a stabilizing yet increasing trend over time. The patterns of spatial distribution showed that the overall level of coordination within the regional economy developed slowly across cities and prefectures with small-scale spatial variation. In other words, the distribution patterns indicated a relatively weak level of coordination, probably caused by the overall low level of economic development in Gansu Province, the weak economic base, significant differences in economic and social development across cities and prefectures, and the irrational industrial structure.

As for the coordination degree within the ecological environment system, the level of coordinated development across 14 cities and prefectures in Gansu Province was relatively stable with an upward trend. Since the tourism industry and related economy started late in Gansu Province, the coordination degree within the ecological environment system was relatively stable at an early stage. With the subsequent large-scale exploitation of tourism resources, the negative impact on the ecological environment became severe, and the level of coordination began to drop. As a response to the increasingly prominent ecological and environmental problems, environmental protection efforts have continued to increase, accompanied by the optimization and upgrading of the industrial structure. As a result, the level of coordination within the ecological environment system started to display some encouraging signs. The patterns of spatial distribution showed that the overall level of coordination within the ecological environment displayed a promising trend across cities and prefectures, with small-scale spatial variation and stable spatial evolution. In particular, the level of coordination was higher in the northwestern part of the Hexi Corridor and the central area of Gansu Province than that of the eastern part. 
Table 5. The within-system coordination degree of 14 cities and prefectures in Gansu Province.

\begin{tabular}{|c|c|c|c|c|c|c|c|}
\hline Name & Subsystem & 2001 & 2004 & 2007 & 2010 & 2013 & 2016 \\
\hline \multirow{3}{*}{ Lanzhou } & $\mathrm{A}$ & 0.1781 & 0.0748 & 0.1695 & 0.2990 & 0.7102 & 0.6728 \\
\hline & B & 0.1053 & 0.1422 & 0.1769 & 0.2604 & 0.3355 & 0.3776 \\
\hline & $\mathrm{C}$ & 0.4166 & 0.3282 & 0.2445 & 0.2262 & 0.2455 & 0.1589 \\
\hline \multirow{3}{*}{ Jiayuguan } & $\mathrm{A}$ & 0.1297 & 0.0499 & 0.1380 & 0.1865 & 0.4503 & 0.4242 \\
\hline & B & 0.0787 & 0.2313 & 0.2723 & 0.3297 & 0.4683 & 0.5393 \\
\hline & $\mathrm{C}$ & 0.8384 & 0.9013 & 0.9255 & 0.8726 & 0.8982 & 0.9145 \\
\hline \multirow{3}{*}{ Jinchang } & $\mathrm{A}$ & 0.0104 & 0.0243 & 0.0011 & 0.0662 & 0.2172 & 0.2005 \\
\hline & B & 0.0704 & 0.3633 & 0.3716 & 0.1659 & 0.1874 & 0.2427 \\
\hline & $\mathrm{C}$ & 0.3963 & 0.1464 & 0.5311 & 0.7121 & 0.7102 & 0.8573 \\
\hline \multirow{3}{*}{ Baiyin } & A & 0.0197 & 0.0049 & 0.0667 & 0.1416 & 0.2892 & 0.3071 \\
\hline & $\mathrm{B}$ & 0.0278 & 0.0806 & 0.1045 & 0.1329 & 0.1667 & 0.2015 \\
\hline & $\mathrm{C}$ & 0.2344 & 0.2052 & 0.5349 & 0.5881 & 0.6751 & 0.8268 \\
\hline \multirow{3}{*}{ Tianshui } & $\mathrm{A}$ & 0.1416 & 0.1807 & 0.2246 & 0.5135 & 0.7517 & 0.8283 \\
\hline & $\mathrm{B}$ & 0.0136 & 0.0498 & 0.0668 & 0.0843 & 0.0997 & 0.1249 \\
\hline & $\mathrm{C}$ & 0.6449 & 0.5981 & 0.6097 & 0.6028 & 0.5792 & 0.5689 \\
\hline \multirow{3}{*}{ Wuwei } & $\mathrm{A}$ & 0.0407 & 0.0692 & 0.1096 & 0.1647 & 0.3058 & 0.3257 \\
\hline & B & 0.0298 & 0.0654 & 0.0749 & 0.1005 & 0.1291 & 0.1501 \\
\hline & $\mathrm{C}$ & 0.6013 & 0.6005 & 0.6333 & 0.6052 & 0.6313 & 0.6337 \\
\hline \multirow{3}{*}{ Zhangye } & $\mathrm{A}$ & 0.0536 & 0.0881 & 0.1306 & 0.1729 & 0.4769 & 0.4638 \\
\hline & B & 0.0215 & 0.0885 & 0.0929 & 0.0760 & 0.1614 & 0.1683 \\
\hline & $\mathrm{C}$ & 0.5683 & 0.5381 & 0.6529 & 0.6948 & 0.7398 & 0.7887 \\
\hline \multirow{3}{*}{ Pingliang } & A & 0.0878 & 0.1004 & 0.1474 & 0.3854 & 0.5818 & 0.6425 \\
\hline & B & 0.0174 & 0.0661 & 0.0717 & 0.0992 & 0.1082 & 0.1369 \\
\hline & $\mathrm{C}$ & 0.6626 & 0.6886 & 0.7724 & 0.7138 & 0.7589 & 0.7846 \\
\hline \multirow{3}{*}{ Jiuquan } & $\mathrm{A}$ & 0.0564 & 0.2863 & 0.3296 & 0.4091 & 0.7264 & 0.8004 \\
\hline & B & 0.0917 & 0.0914 & 0.1359 & 0.2581 & 0.2938 & 0.3455 \\
\hline & $\mathrm{C}$ & 0.7736 & 0.7222 & 0.7693 & 0.7148 & 0.7458 & 0.7262 \\
\hline \multirow{3}{*}{ Qingyang } & $\mathrm{A}$ & 0.0189 & 0.0194 & 0.0167 & 0.0531 & 0.1508 & 0.1410 \\
\hline & B & 0.0190 & 0.0720 & 0.0749 & 0.1212 & 0.1649 & 0.1927 \\
\hline & $\mathrm{C}$ & 0.5979 & 0.5610 & 0.5446 & 0.5245 & 0.5387 & 0.5069 \\
\hline \multirow{3}{*}{ Dingxi } & $\mathrm{A}$ & 0.1563 & 0.0437 & 0.1743 & 0.2396 & 0.2541 & 0.2911 \\
\hline & B & 0.0100 & 0.0204 & 0.0620 & 0.0586 & 0.0636 & 0.0865 \\
\hline & $\mathrm{C}$ & 0.4600 & 0.4588 & 0.4627 & 0.4669 & 0.5037 & 0.4991 \\
\hline \multirow{3}{*}{ Longnan } & $A$ & 0.0556 & 0.0452 & 0.1347 & 0.1237 & 0.4436 & 0.4169 \\
\hline & B & 0.0067 & 0.0513 & 0.0599 & 0.0613 & 0.1010 & 0.1156 \\
\hline & $\mathrm{C}$ & 0.3083 & 0.3073 & 0.3180 & 0.3046 & 0.3185 & 0.3167 \\
\hline \multirow{3}{*}{ Linxia } & $\mathrm{A}$ & 0.0706 & 0.1281 & 0.1298 & 0.1156 & 0.2893 & 0.2742 \\
\hline & B & 0.0166 & 0.0232 & 0.0390 & 0.0412 & 0.1049 & 0.1034 \\
\hline & $\mathrm{C}$ & 0.4987 & 0.5233 & 0.5552 & 0.5124 & 0.5311 & 0.5403 \\
\hline \multirow{3}{*}{ Gannan } & A & 0.2907 & 0.3266 & 0.2295 & 0.2176 & 0.3830 & 0.3122 \\
\hline & B & 0.0114 & 0.0391 & 0.0507 & 0.0720 & 0.0813 & 0.1027 \\
\hline & $\mathrm{C}$ & 0.4372 & 0.4248 & 0.4498 & 0.4572 & 0.4592 & 0.4686 \\
\hline
\end{tabular}

3.2. The Assessment and Analysis of the between-System Coordination Degree

\subsubsection{The Assessment and Analysis of Gansu Province}

It can be seen from Figure 3 that the overall coordination degree between the tourism industry, regional economy and ecological environment systems of Gansu Province was no less than 0.5 between 2000 and 2016. The trend has kept increasing in recent years with an irregular variation. Between 2000 and 2004, the coordination degree between systems displayed a trend of fluctuating 
evolution, but with a small-scale variation, except for an obvious drop in 2002. Between 2005 and 2016 , the coordination degree between systems fluctuated continuously with an increased variation. The rapid development of the regional economy promoted the development of the tourism industry, and the latter, to a certain extent, also facilitated the former. However, the development of the tourism industry inevitably imposed a negative impact on the quality of the ecological environment, therefore canceling out one another. Thus, the overall coordination degree between systems displayed an irregular evolution pattern.

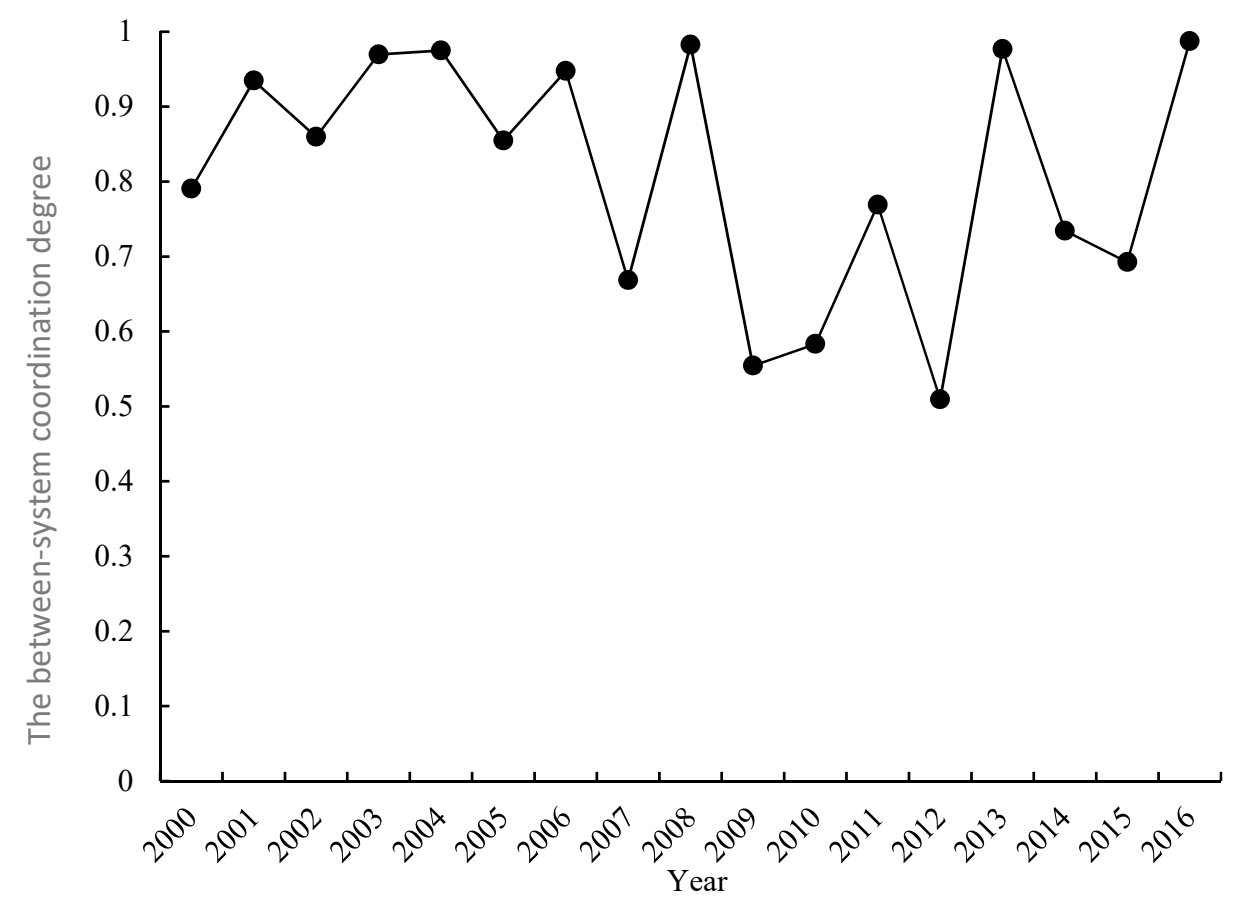

Figure 3. The between-system coordination degree of Gansu Province.

\subsubsection{The Assessment and Analysis of Cities}

According to the coordination measurement model between systems, the coordination degree between the tourism industry, regional economy and ecological environment subsystems of 14 cities in Gansu Province in 2001, 2004, 2007, 2010, 2013 and 2016 was quantified, with A representing the tourism industry, B representing the regional economy, and C representing the ecological environment.

It can be seen from Table 6 that between 2001 and 2016, the coordination degree between the tourism industry, regional economy and ecological environment systems in cities generally displayed a strong development trend. However, the existence of a large variation also suggested that the level of coordination between the systems was relatively unstable, and further adjustment was needed. Such a large variation was found particularly in some cities and prefectures, and a few even showed a decreasing trend, suggesting that differences in development clearly existed between the tourism industry, regional economy and ecological environment subsystems. Therefore, the level of coordination between subsystems not only depended on their developmental level, but also relied on the level of coordinated development between them. In other words, the level of coordination between subsystems might only be improved if the level of coordinated development between them was effectively enhanced. The pattern of spatial distribution revealed that the coordination degree between systems across cities and prefectures displayed an irregular evolutionary trend. In spite of a large-scale spatial variation, the coordination degree between systems was improved as a whole. Other scholars also have carried out some relevant researches. The representative example is Han's research. Based on the model of coupling coordination degree, Han [16] took the 16 prefectural-level 
cities in the Yangtze river delta as an example, analyzed the temporal and spatial evolution of coupling coordinated development between the tourism industry and ecological environment. The results showed that, for all the prefectural-level cities in the Yangtze river delta, coupling coordinated degree experienced a large variation, and the spatial classification was changing. It is in correspondence with the result of this study. It also shows the evolution of coordinated development between tourism industry and ecological environment at prefectural-level cities in China. But it has not included the subsystem of regional economy, and a further research for three subsystems has not been conducted.

Table 6. The between-system coordination degree of 14 cities and prefectures in Gansu Province.

\begin{tabular}{cccccccc}
\hline Name & $\mathbf{U}$ & $\mathbf{2 0 0 1}$ & $\mathbf{2 0 0 4}$ & $\mathbf{2 0 0 7}$ & $\mathbf{2 0 1 0}$ & $\mathbf{2 0 1 3}$ & $\mathbf{2 0 1 6}$ \\
\hline Lanzhou & $\mathrm{U}(\mathrm{A}, \mathrm{B}, \mathrm{C})$ & 0.5654 & 0.4387 & 0.8175 & 0.7801 & 0.3115 & 0.5327 \\
Jiayuguan & $\mathrm{U}(\mathrm{A}, \mathrm{B}, \mathrm{C})$ & 0.6547 & 0.6318 & 0.5848 & 0.8301 & 0.6159 & 0.6997 \\
Jinchang & $\mathrm{U}(\mathrm{A}, \mathrm{B}, \mathrm{C})$ & 0.8705 & 0.7268 & 0.7730 & 0.3994 & 0.6968 & 0.4909 \\
Baiyin & $\mathrm{U}(\mathrm{A}, \mathrm{B}, \mathrm{C})$ & 0.7110 & 0.7163 & 0.8137 & 0.7493 & 0.8995 & 0.9010 \\
Tianshui & $\mathrm{U}(\mathrm{A}, \mathrm{B}, \mathrm{C})$ & 0.8281 & 0.7669 & 0.8080 & 0.9701 & 0.9134 & 0.9694 \\
Wuwei & $\mathrm{U}(\mathrm{A}, \mathrm{B}, \mathrm{C})$ & 0.9456 & 0.9183 & 0.8869 & 0.5628 & 0.8431 & 0.6632 \\
Zhangye & $\mathrm{U}(\mathrm{A}, \mathrm{B}, \mathrm{C})$ & 0.8651 & 0.9675 & 0.9539 & 0.9780 & 0.9813 & 0.9886 \\
Pingliang & $\mathrm{U}(\mathrm{A}, \mathrm{B}, \mathrm{C})$ & 0.8749 & 0.9438 & 0.8360 & 0.8390 & 0.9456 & 0.8988 \\
Jiuquan & $\mathrm{U}(\mathrm{A}, \mathrm{B}, \mathrm{C})$ & 0.9797 & 0.8693 & 0.7307 & 0.8298 & 0.9646 & 0.8539 \\
Qingyang & $\mathrm{U}(\mathrm{A}, \mathrm{B}, \mathrm{C})$ & 0.5731 & 0.2769 & 0.5711 & 0.6952 & 0.6743 & 0.7443 \\
Dingxi & $\mathrm{U}(\mathrm{A}, \mathrm{B}, \mathrm{C})$ & 0.9243 & 0.8489 & 0.9562 & 0.9417 & 0.9791 & 0.9908 \\
Longnan & $\mathrm{U}(\mathrm{A}, \mathrm{B}, \mathrm{C})$ & 0.3206 & 0.6800 & 0.7553 & 0.5412 & 0.6515 & 0.7466 \\
Linxia & $\mathrm{U}(\mathrm{A}, \mathrm{B}, \mathrm{C})$ & 0.8543 & 0.7307 & 0.9052 & 0.8875 & 0.9328 & 0.9562 \\
Gannan & $\mathrm{U}(\mathrm{A}, \mathrm{B}, \mathrm{C})$ & 0.4888 & 0.4992 & 0.4174 & 0.5129 & 0.4990 & 0.4937 \\
\hline
\end{tabular}

\subsection{The Overall Assessment and Analysis of the Coordinated Development}

\subsubsection{The Assessment and Analysis of Gansu Province}

It can be seen from Figure 4 that between 2000 and 2016, the overall coordination development in Gansu Province showed a promising trend. In particular, the level of coordinated development between 2000 and 2012 maintained a relatively stable growth. There was a dramatic increase in 2013, suggesting that Gansu Province was gradually moving in the right direction regarding coordinated development, although it should be noted that coordinated development in this area was still at a moderate level, and further improvement was needed. Overall, the process of coordination development in Gansu Province experienced four phases, which was a transition from the state of uncoordinated to basically coordinated, basically coordinated to fairly coordinated, and fairly coordinated to highly coordinated. The average value of its coordinated development was 0.6079 , suggesting that as a whole Gansu Province is in a state of basically coordinated. Between 2000 and 2012, Gansu Province was in a transition from the state of uncoordinated to basically coordinated; whereas in 2013, it was in a transition from the state of basically coordinated to fairly coordinated due to further enhancement of the coordinated development between the regional economy, tourism industry and ecological environment, although further improvement was still needed. After 2014, the coordination development in Gansu Province is in the state of highly coordinated. 


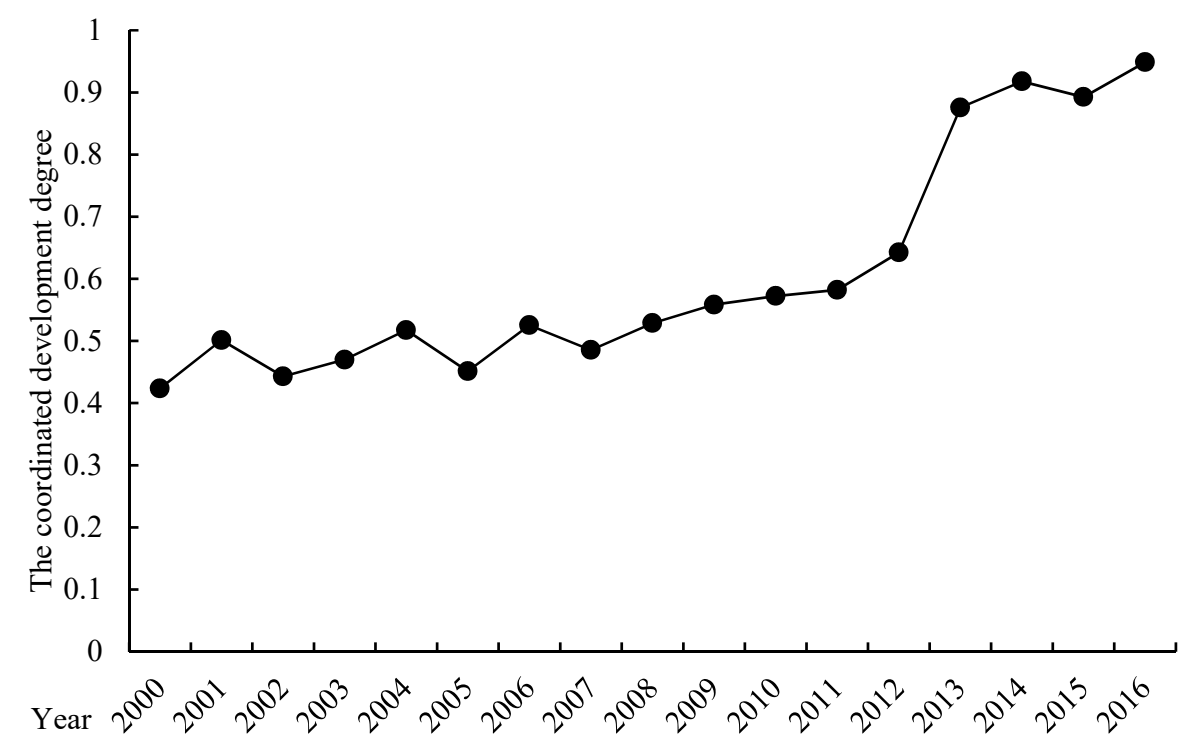

Figure 4. The coordinated development degree of Gansu Province.

\subsubsection{The Assessment and Analysis of Cities and Prefectures}

It can be seen from Table 7 that between 2001 and 2016, the degree of coordinated development of 14 cities showed a general upward trend, but some differences in spatial distribution still existed. For example, the level of coordinated development between Lanzhou city and Jiayuguan city showed a relatively fluctuating evolutionary trend when compared to the rest of the cities and prefectures with a more stable development trend. Between 2001 and 2010, the level of coordinated development between cities and prefectures displayed an evolutionary development trend in an intercrossing and interactive manner. Since 2010, the level of coordinated development across cities has shown a relatively stable pattern. Furthermore, the value of the coordination development degree gradually kept on increasing, and the overall development was promising. The coordinated development of cities and prefectures in Gansu Province could be divided into five levels (Figure 5). Overall, the degree of coordinated development among cities and prefectures showed a gradually increasing trend, signaling a state of strong development. Judging from the average degree of coordinated development of each city and prefecture in Gansu Province, the range of the average value was between 0.44 and 0.66, indicating a state of basically coordinated. However, since these cities had their own specific situations and special occasions, the degree of coordinated development still displayed some spatial differences. In particular, the middle and eastern part of Gansu Province represented a highly coordinated region, which meant a relatively good level of coordinated development in this region. By contrast, the Hexi Corridor and south Gansu Province showed lower levels of coordinated development. Other scholars also have carried out some relevant researches. The representative example is Zhang's research. Based on the model of coordination development degree, Zhang [15] took all the prefectural-level cities in Jiangxi province as an example, analyzed the coupling coordinated development between the tourism and ecological environment. The results showed that, for all the prefectural-level cities in Jiangxi province, the coordinated development degree between tourism and ecological environment was steadily increasing, and the coordinated development level was gradually improving. It is in correspondence with the result of this study. It also shows the evolution of coordinated development between tourism and ecological environment at prefectural-level cities in China. But it has not included the subsystem of regional economy, and a further research for three subsystems has not been conducted. 


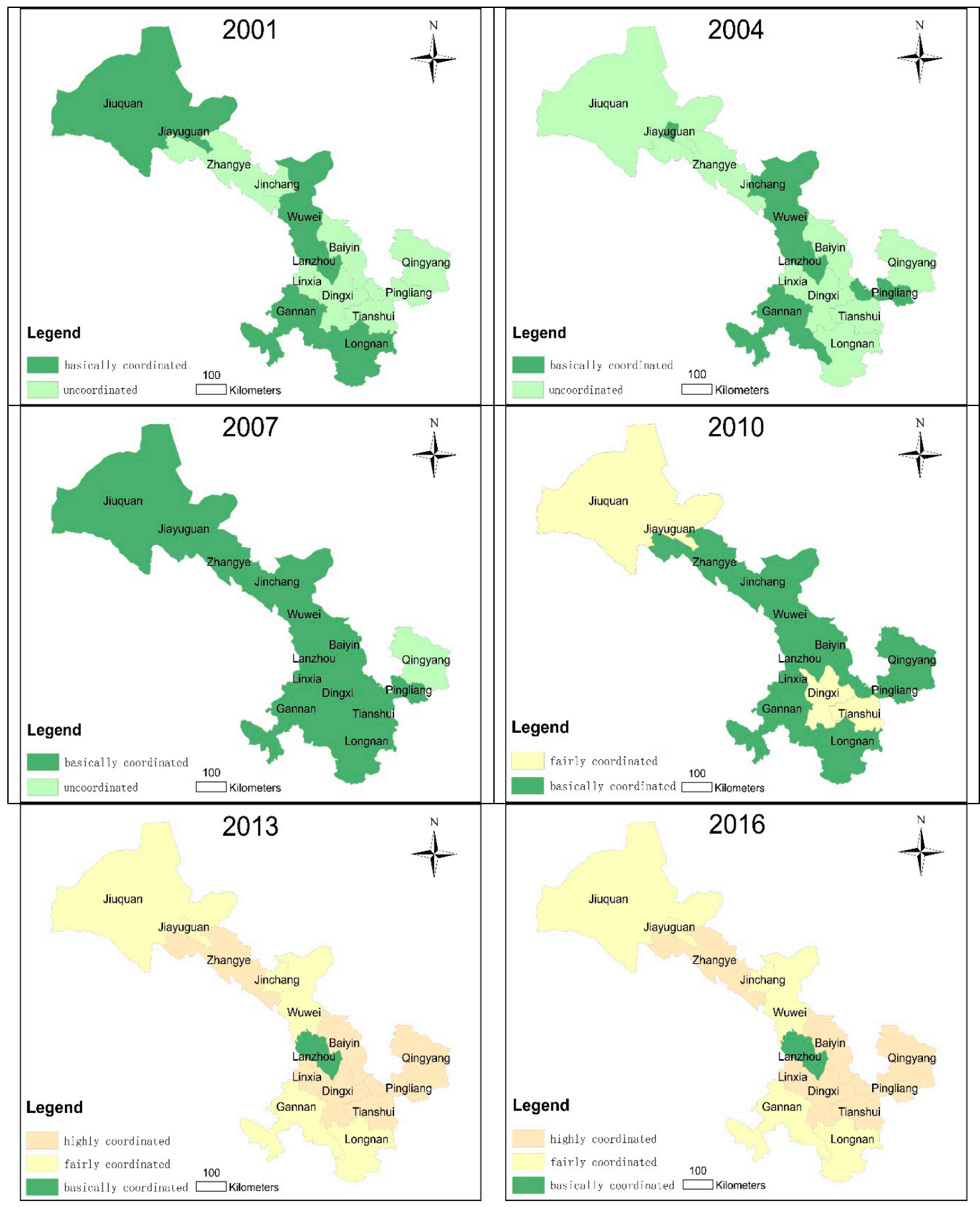

Figure 5. The distribution of coordinated development degree in Gansu Province.

Table 7. The coordinated development degree of 14 cities and prefectures in Gansu Province.

\begin{tabular}{ccccccc}
\hline Name & $\mathbf{2 0 0 1}$ & $\mathbf{2 0 0 4}$ & $\mathbf{2 0 0 7}$ & $\mathbf{2 0 1 0}$ & $\mathbf{2 0 1 3}$ & $\mathbf{2 0 1 6}$ \\
\hline Lanzhou & 0.5711 & 0.6139 & 0.4489 & 0.5165 & 0.6448 & 0.5740 \\
Jiayuguan & 0.4526 & 0.4420 & 0.5516 & 0.7467 & 0.6983 & 0.8171 \\
Jinchang & 0.4203 & 0.5888 & 0.5533 & 0.5897 & 0.7382 & 0.7691 \\
Baiyin & 0.4088 & 0.3969 & 0.6203 & 0.6341 & 0.9147 & 0.9697 \\
Tianshui & 0.3973 & 0.3662 & 0.4579 & 0.7516 & 0.8839 & 0.9790 \\
Wuwei & 0.5581 & 0.4705 & 0.5592 & 0.5931 & 0.8040 & 0.7813 \\
Zhangye & 0.4002 & 0.4193 & 0.5014 & 0.6391 & 0.8910 & 0.9306 \\
\hline
\end{tabular}


Table 7. Cont.

\begin{tabular}{ccccccc}
\hline Name & $\mathbf{2 0 0 1}$ & $\mathbf{2 0 0 4}$ & $\mathbf{2 0 0 7}$ & $\mathbf{2 0 1 0}$ & $\mathbf{2 0 1 3}$ & $\mathbf{2 0 1 6}$ \\
\hline Pingliang & 0.4152 & 0.5125 & 0.4996 & 0.6002 & 0.9755 & 0.9631 \\
Jiuquan & 0.4910 & 0.4083 & 0.5042 & 0.7057 & 0.8098 & 0.8643 \\
Qingyang & 0.4108 & 0.4327 & 0.4091 & 0.6289 & 0.9012 & 0.9096 \\
Dingxi & 0.4044 & 0.3752 & 0.5511 & 0.6931 & 0.9742 & 0.9811 \\
Longnan & 0.4479 & 0.4337 & 0.5562 & 0.5274 & 0.7675 & 0.7664 \\
Linxia & 0.3878 & 0.3938 & 0.5407 & 0.5125 & 0.9829 & 0.9562 \\
Gannan & 0.5107 & 0.5325 & 0.4972 & 0.6542 & 0.7841 & 0.7963 \\
\hline
\end{tabular}

\section{Conclusions}

Between 2000 and 2016, the development of the regional economy, tourism industry and ecological environment mutually reinforced one another in Gansu Province. Overall, the level of coordinated development kept gradually improving over time. However, the development of the ecological environment lagged behind that of the tourism industry and economic growth, and synchronous and coordinated development among these three subsystems was not achieved. The overall level of coordination among cities and prefectures was also gradually improved, as manifested by the good level of coordinated development. However, spatial differences still existed. For example, the level of coordinated development was relatively higher in the central and eastern part of Gansu Province, followed by the Hexi Corridor and the southern part. For some of the rest of the cities and prefectures however, the picture regarding the level of coordinated development among subsystems was not all that encouraging, and a synchronous and coordinated development among subsystems was lacking to a large degree. In summary, different cities and prefectures of Gansu Province have worked hard to progressively implement the strategy of sustainable development, and to actively optimize the upgrading of the industrial structure. Moreover, the level of coordinated development among the regional economy, tourism industry and ecological environment has achieved some initial success. However, a focus on overall coordination should be prioritized in order to strengthen the coordinated development between systems.

Through the development of a series of comprehensive measurement models that could accurately quantify the within-system coordination degree, between-system coordination degree and the degree of coordinated development, we are able to conduct a comprehensive measurement analysis regarding the level of coordinated development between the regional economy, tourism industry and ecological environment, and to realize spatiotemporal synthetic measurements across different spatial scales. Taking Gansu Province as an example, this research explored the temporal and spatial evolution of the coordination of development of tourism, economy and ecological environment. It can provide scientific basis for the coordinated development between tourism, economy and ecological environment in Gansu Province, and also provide guidance for the sustainable, healthy and stable development of regional tourism. Moreover, it can provide reference for the implementation of sustainable development strategy. Thus, this research has important practical significance. Overall, the level of coordinated development between the regional economy, tourism industry and ecological environment in Gansu province kept gradually improving. However, the level of coordinated development among these three subsystems remains unsatisfactory, which requires further improvement. To serve that purpose, the level of coordinated development between systems needs to become a key factor or an action priority. Therefore, effective measures should be taken in order to ensure a coordinated development within systems in general, and to promote a synchronous and coordinated development between systems in particular. If this occurs, the goal of realizing a full-scale coordination and sustainable development between the regional economy, the tourism industry, and ecological environment could eventually be achieved. The detailed recommendations are proposed as follows. It includes changing the pattern of tourism development, optimizing the spatial distribution of tourism, adjusting and optimizing the industrial structure, perfecting the laws and regulations of environmental 
protection, and coordinating the regional development. Through these targeted recommendations, the coordinated and sustainable development of tourism, economy and ecological environment can be achieved.

There are still some defects in this study. The first defect is the selection of indexes. As a result of the individual subjectivity and the limitation of regional actual situation, there is certain subjectivity for selecting indexes. Therefore, it is difficult to establish an evaluation index system that is completely objective. The second defect is the limitation of data. Due to lack of data before 2000, this research only conducts an empirical analysis for the coordinated development between tourism, economy and ecological environment at provincial level from 2000 to 2016. As it is particularly difficult to obtain the data of prefectural-level cities, only partial years' data are selected for studying, and continuous time series analysis is not carried out. These defects will be further improved in the future research.

Acknowledgments: We are grateful for financial supports of Natural Science Foundation of China (No. 41561110; No. 41261112; No. 41471116; No. 41461119), the Science and Technology Support Program of Gansu Province (No. 1304FKCA067), International Exchange Fellowship Program of China Postdoctoral Council (20140050). Special thanks go to the Open-Fund of the CAS Key Laboratory of Pollution Ecology and Environmental Engineering (Y3ZDS171YC) and the Youth Innovation Promotion Association CAS (2016181).

Author Contributions: Chenyu Lu and Bing Xue designed the study and wrote the paper. Wenlei Li and Hong Miao analyzed the data. Min Pang contributed to data collection and processing. All authors read and approved the manuscript.

Conflicts of Interest: The authors declare no conflict of interest.

\section{References}

1. Fang, Y.L.; Huang, Z.F.; Wang, K.; Tu, W. Spatial and temporal analysis of Chinese provincial tourism economy based on PCA-ESDA. Econ. Geogr. 2012, 32, 149-154. (In Chinese)

2. Su, J.J.; Zhang, Y.; Sun, G.N. Analysis of the pulling effect and contribution of tourism consumption on economic growth in China. Consum. Econ. 2016, 1, 34-40. (In Chinese)

3. Su, J.J.; Sun, G.N.; Xu, Z.Y. The pull effect of tourism development on demands for investment, consumption and exports in China. Tour. Trib. 2014, 29, 25-35. (In Chinese)

4. Zheng, Q.X.; Kuang, Y.Q.; Huang, N.S. Spatio-Temporal evolution of coordinated development of tourism economy and ecological environment in Guangdong province. Acta Agric. Jiangxi 2017, 29, 108-113. (In Chinese)

5. Milman, A.; Pizam, A. Social Impacts of Tourism on Central Florida. Ann. Tour. Res. 1988, 15, $191-204$. [CrossRef]

6. Oh, C. The contribution of tourism development to economic growth in the Korean economy. Tour. Manag. 2005, 26, 39-44. [CrossRef]

7. Lee, C.C.; Chang, C.P. Tourism development and economic growth: A closer look at panels. Tour. Manag. 2008, 29, 180-192. [CrossRef]

8. Cao, S.Y.; Bai, L. A study on coordinating urban agglomeration's leisure sports industry cluster and regional economic and social development in Yangtze River Delta. Urban Insight 2010, 6, 72-78. (In Chinese)

9. Liu, J.D.; Zheng, X.M.; Xie, C.W. A study on the provincial coupling coordinative degree between tourism industry and regional economy in China. Tour. Forum 2013, 6, 42-47. (In Chinese)

10. Gossling, S.; Peeters, P. Assessing tourism's global environmental impact 1900-2050. J. Sustain. Tour. 2015, 23, 1-21. [CrossRef]

11. Karim, R.; Batra, A.; Muhammad, F.; Shaheen, R.; Perveen, S. An investigation of environmental impact of mountain tourism activities in the Hunza valley of Pakistan: A tourists' perspective. J. Biodivers. Environ. Sci. 2014, 5, 601-609.

12. Hein, L.; Metzger, M.J.; Alvaro, M. Potential impacts of climate change on tourism: A case study for Spain. Curr. Opin. Environ. Sustain. 2009, 1, 170-178. [CrossRef]

13. Day, J.; Cai, L.P. Environmental and energy-related challenges to sustainable tourism in the United States and China. Int. J. Sustain. Dev. World Ecol. 2012, 19, 379-388. [CrossRef]

14. An, Y. Tourism Development and Ecological Environment Protection. J. Landsc. Res. 2015, 43, 89-95.

15. Zhang, S. Study on the coupling coordination development between tourism economy and ecological environment in Jiangxi province. Econ. Forum 2017, 1, 34-37. (In Chinese) 
16. Han, Y.Q.; Zhou, X.M. Analysis on coupling coordination degree of tourism economy and ecological environment in Yangtze river delta region. Sci. Technol. Manag. 2016, 18, 104-109. (In Chinese)

17. Lu, C.Y.; Wang, C.J.; Zhu, W.L.; Li, H.J.; Li, Y.J.; Lu, C.P. GIS-based synthetic measurement of sustainable development in Loess Plateau ecologically fragile area-Case of Qingyang, China. Sustainability 2015, 7, 1576-1594. [CrossRef]

18. Xue, B.; Chen, X.P.; Geng, Y.; Yang, M.; Yang, F.X.; Hu, X.F. Emergy-based study on eco-economic system of arid and semi-arid region-case of Gansu province, China. J. Arid Land 2010, 2, 207-213.

19. Xiong, C.H.; Yang, D.G.; Huo, J.W.; Zhao, Y.N. The relationship between energy consumption and economic growth and the development strategy of a low-carbon economy in Kazakhstan. J. Arid Land 2015, 7, 706-715. [CrossRef]

20. Grossman, G.M.; Krueger, A.B. Economic growth and the environment. Q. J. Econ. 1995, 110, 353-378. [CrossRef]

21. Caviglia-Harris, J.L.; Chambers, D.; Kahn, J.R. Taking the "U" out of Kuznets: A comprehensive analysis of the EKC and environmental degradation. Ecol. Econ. 2009, 68, 1149-1159. [CrossRef]

22. Bithas, K.; Nijkamn, P. Environmental-economic modeling with semantic insufficiency and factual uncertainty. J. Environ. Syst. 1996, 25, 167-183. [CrossRef]

23. Stave, K.A. Using system dynamics to improve public participation in environmental decisions. Syst. Dyn. Rev. 2002, 18, 139-167. [CrossRef]

24. Oliveira, C.; Antunes, C.H. A multi-objective multi-sectorial economy-energy-environment model: Application to Portugal. Energy 2011, 36, 2856-2866. [CrossRef]

25. Yang, Y.; Zhang, X.L.; Lei, J.; Dong, W. Sustainable regional development based on resources exploitation and utilization. Sci. Geogr. Sin. 2010, 30, 363-369. (In Chinese)

26. Cai, B.C.; Lu, G.F.; Han, S.F.; Chen, K.L.; Song, L.J. Evaluation studies on the economic sustainable development of Jiangsu province. China Environ. Sci. 2006, 26, 496-499. (In Chinese)

27. Ren, Z.F.; Li, Y.X. Analysis and evaluation on the level of regional sustainable development in Xinjiang. Sci. Technol. Prog. Policy 2011, 28, 126-129. (In Chinese)

28. Zhang, J.; Li, Q.; Zhou, Y. The evaluation of urban sustainable development in Shanxi province. China Popul. Resour. Environ. 2013, 23, 448-453. (In Chinese)

29. Petrosillo, I.; Zurlini, G.; Grato, E.; Zaccarelli, N. Indicating fragility of socio-ecological tourism-based systems. Ecol. Indic. 2006, 6, 104-113. [CrossRef]

30. Lacitignola, D.; Petrosillo, I.; Cataldi, M.; Zurlini, G. Modelling socio-ecological tourism-based systems for sustainability. Ecol. Model. 2007, 206, 191-204. [CrossRef]

31. Wei, W.; Alvarez, I.; Martin, S. Sustainability analysis: Viability concepts to consider transient and asymptotical dynamics in socio-ecological tourism-based systems. Ecol. Model. 2013, 251, 103-113. [CrossRef]

32. Zhou, C.; Feng, X.G.; Tang, R. Analysis and forecast of coupling coordination development among the regional economy-ecological environment-tourism industry-A case study of provinces along the Yangtze Economic Zone. Econ. Geogr. 2016, 36, 186-193. (In Chinese)

33. Xiong, Y.; Li, C.L. Synthetic evaluation on coordinated of tourism-economy-ecological system in Zhangjiajie city. China Popul. Resour. Environ. 2014, 24, 246-250. (In Chinese)

34. Wang, B.; Fang, L. The evaluation model of the degree of balanced development of district economy. J. China Univ. Geosci. (Soc. Sci. Ed.) 2004, 4, 52-55. (In Chinese)

(c) 2018 by the authors. Licensee MDPI, Basel, Switzerland. This article is an open access article distributed under the terms and conditions of the Creative Commons Attribution (CC BY) license (http:/ / creativecommons.org/licenses/by/4.0/). 